\title{
Koroner Arter Cerrahisinin Solunum Fonksiyonlarına Etkilerinin Solunum Fonksiyon Testi ile Değerlendirilmesi
}

\section{Evaluation of the Effects of Coronary Artery Surgery on Pulmonary Functions by Pulmonary Function Test}

\author{
Tolga Onur Badak ${ }^{1 *}$, Ahmet İhsan İşkesen ${ }^{2}$ \\ ${ }^{1}$ Adana Şehir Eğitim ve Araştırma Hastanesi, Kalp ve Damar Cerrahi Kliniği, Adana, Türkiye \\ ${ }^{2}$ Manisa Celal Bayar Üniversitesi Tıp Fakültesi Hastanesi, Kalp ve Damar Cerrahisi Anabilim Dalı, Manisa, \\ Türkiye
}

\author{
e-mail: tolgaonurbadak_dr@hotmail.com, iskesen@yahoo.com \\ ORCID: 0000-0001-7957-3423 \\ ORCID: 0000-0003-3771-4827 \\ *Sorumlu yazar/ Corresponding Author: Tolga Onur Badak
}

\author{
Gönderim Tarihi / Received: 08.01.2021 \\ Kabul Tarihi / Accepted: 26.03.2021 \\ DOI: $10.34087 /$ cbusbed. 856434
}

\section{$\ddot{O} z$}

Giriş ve Amaç: Kronik Obstrüktif Akciğer Hastalığı (KOAH), koroner arter bypass greft operasyonu (CABG) yapılan hastalarda sık bir komorbid hastalıktır ve insidans $\% 4$ ile \%20,5 aralığındadır. KOAH geleneksel olarak CABG için cerrahi kontraendikasyon olarak bilinir. Cerrahi teknik, anestezi ve postoperatif hasta yönetimindeki son gelişmelerden dolayı CABG artık KOAH'lı hastalarda çok yaygın bir şekilde yapılmaktadır. Ancak son çalışmalar, CABG sonrası postoperatif mortalite ve morbidite üzerine KOAH'ın çeşitli etkilerini göstermiştir. Çalışmamızda CABG ameliyatının solunum fonksiyonlarına etkisini preoperatif ve postoperatif dönemde yapılan solunum fonksiyon testi ile araştırmayı amaçladık.

Gereç ve Yöntemler: Kliniğimizde izole CABG cerrahisi uygulanan 50 hasta çalışmaya dahil edildi. Preoperatif solunum fonksiyon testinde FEV1 değeri $<\% 70$ olan toplam 24 hasta KOAH grubunu (Grup 1), geri kalan 26 hasta ise kontrol grubunu (Grup 2) oluşturdu.

Bulgular: KOAH grubunda mekanik ventilasyonda kalış süresi (Grup 1'de $16.5 \pm 2.6$ saat, Grup 2'de $14.9 \pm 2.7$ saat; $\mathrm{p}=0.0001$ ) ve hastanede yatıș süreleri (Grup 1'de $13.8 \pm 5.4$ gün, Grup 2'de $10.1 \pm 2.5$ gün; $\mathrm{p}=0.004$ ) bakımından kontrol grubuna göre anlamlı olarak uzamış idi. Solunum fonksiyon test parametrelerine bakıldığında KOAH grubunda zaten düşük olan değerlerde anlamlı bir düşme gözlenmezken, Kontrol grubunda postoperatif değerlerde preoperatif değerlere göre anlamlı bir düşme gözlenmiştir.

Sonuç: CABG ameliyatı geçirecek hastalara preoperatif dönemde KOAH tanısının konması ve şiddetinin belirlenmesi; preoperatif dönemde gerekli tedavinin başlanması, intraoperatif ve postoperatif dönemde gelişebilecek komplikasyonları azaltmak ve/veya önlemek, takip edilecek stratejiler ve alınacak önlemler açısından önemlidir. Bu nedenle CABG ameliyatı olacak her hastaya preoperatif dönemde solunum fonksiyon testi rutin olarak uygulanmalıdır.

Anahtar kelimeler: Kronik Obstrüktif Akciğer Hastalığı, Koroner Arter Bypass Grefti, Solunum Fonksiyon Testi.

\section{Abstract}

Objective: Chronic obstructive pulmonary disease (COPD) is a frequent comorbid disease in patients undergoing coronary artery bypass grafting (CABG) surgery, with an incidence ranging from $4 \%$ to $20.5 \%$. Conventionally, COPD was recognized as a surgical contraindication to CABG. Because of the recent improvements in surgical techniques, anesthesia, and postoperative management, CABG has been performed more commonly in patients with COPD. However, studies have shown the various effects of COPD on postoperative morbidity and mortality after CABG. In our study, we aimed to investigate the effect of CABG surgery on respiratory functions with the respiratory function test performed in the preoperative and postoperative periods. 
Materials and Methods: Fifty patients who underwent isolated CABG surgery in our clinic were included in the study. 24 Patients with preoperative FEV1 value $<\% 70$ were taken into COPD group (Group 1) and the remaining 26 patients were taken into control group (Group 2) according to the respiratory function tests.

Results: In COPD group mechanical ventilation time (Group 1: $16.5 \pm 2.6$ hours, Grup 2: $14.9 \pm 2.7$ hours; $p=0.0001$ ) and hospital stay (Group 1: $13.8 \pm 5.4$ days, Group 2: $10.1 \pm 2.5$ days; $\mathrm{p}=0.004$ ) were significantly increased compared to the control group. Pulmonary function parameters were not significantly changed in COPD group but on the other hand significant decrease in postoperative values was seen in the control group.

Conclusion: The diagnosis, evaluation and start of appropriate treatment of COPD in preoperative period are significantly important factors in order to reduce of respiratory complications during postoperative period in $\mathrm{CABG}$ patients. For this reason preoperative respiratory function tests should be applied routinely in CABG patients.

Keywords: Chronic Obstructive Pulmonary Disease, Coronary Artery Bypass Greft Surgery, Respiratory Function Tests.

\section{Giriş}

Kronik obstrüktif akciğer hastalığı (KOAH) yavaş ilerleyiş gösteren ölümcül bir hastalık olup dünya çapında yaşa standardize edilmiş üçüncü önde gelen ölüm sebebidir. Her yıl yaklaşı 3.2 milyon hasta bu hastalıktan ölmektedir [1]. KOAH; hava yollarının, alveollerin ve mikrovasküler yatağın kalıcı hava akım sınırlanması ve küçük havayollarının remodelingi ile seyreden inflamatuar hastalığıdır [2]. KOAH, koroner arter bypass greft operasyonu (CABG) yapilan hastalarda sık görülen komorbid bir hastalık olup insidans $1 \% 4$ ile $\% 20,5$ aralığındadır $[2,3]$. KOAH geleneksel olarak $\mathrm{CABG}$ için cerrahi kontraendikasyon olarak bilinir. Günümüzde cerrahi teknik, anestezi ve postoperatif hasta yönetimindeki son gelişmelerden dolayı CABG, KOAH'lı hastalarda çok yaygın bir şekilde yapılmaktadır. CABG ameliyatı için endike hastalarda KOAH artmış mortalite ve morbidite (uzamış mekanik ventilasyon, solunum yetmezliği ve atriyal fibrilasyon gibi) ile iliş̧kili rapor edilmiştir [2, 4]. Mortalite oranları açısından KOAH olmayanlar, hafif, orta ve ciddi KOAH'lı hastalar kıyaslandığında ciddi KOAH'lı hastalarda mortalitenin arttığ 1 rapor edilmiştir $[2,5]$.

Akciğer hastalığı olan hastalarda CABG sonrasında hastanın yaşam kalitesi ileri derecede düşmekte ve postoperatif dönemde hastanın hayatını riske eden komplikasyonlar gelişmektedir. CABG ameliyatı olan hastaların preoperatif FEV1 düzeylerinin düşük olması uzamış entübasyon için bir risk oluşturduğu ve postoperatif dönemde de bu hastalarda yüksek reentübasyon oranlarına sahip olduğu bilinmektedir [6].

CABG cerrahisi sirasinda kullanılan kardiopulmoner bypass (CPB) bazı inflamatuar sistemleri aktive ederek (kompleman sistemin aktivasyonu, pulmoner mikrovasküler yatakta nötrofil sekestrasyonu, oksijen kaynaklı serbest radikallerin salınmasına yol açması) alveolar stabiliteyi artırmakta ve alveolar surfaktanın yapısını bozmaktadır [7, 8]. Ayrıca sternotomi de restriktif tarzda akciğer kapasitesini azaltarak KOAH hastalarının postoperatif pulmoner fonksiyonlarına zarar vermektedir [9]. CPB süresince akciğerler fonksiyon dışı kaldığı ve akciğerlere hava gitmediği için CPB sonrasında tekrar solunum başladığında atelektazi görülebilmektedir [10]. CABG sonrası vital kapasite, inspiratuar kapasite, fonksiyonel rezidüel kapasite, total akciğer kapasitesi ve difüzyon kapasitesinde düşme

görülmekte ve bu değerlerin eski haline dönmesi birkaç ayı bulmaktadır [11].

Biz çalışmamızda KOAH'ın CABG sonrası morbiditeye etkisi ile CABG'nin solunum fonksiyonları üzerine etkisini araştırmayı amaçladık.

\section{Materyal ve Metot}

İzole CABG ameliyat1 yapılan 50 hastaya preoperatif dönemde ve postoperatif 1 . haftada yapılan solunum fonksiyon test (SFT) verileri prospektif olarak kaydedildi. Bu hastalardan preoperatif SFT'de FEV1 değeri $<\% 70$ olan 24 hasta KOAH grubu (Grup 1) olarak kabul edildi. Geri kalan 26 hasta ise kontrol grubunu oluşturdu (Grup 2). Hastaların yaş, cinsiyet, sigara kullanımı, postoperatif mekanik ventilatörde kalma süresi, yoğun bakımda yatı̧̧ ve hastanede yatış süreleri gibi verileri kaydedildi.

CABG dışında yapılan açık kalp cerrahisi hastaları ile SFT'ni yapamayacak kadar işitsel, zihinsel ve psikolojik problemi olan hastalar çalışma dışı bırakıldı.

Çalışmamızda SFT için Flowhandy ZAN 100 USB Spirometre (ZAN Messgerate, Oberthulba, Germany) cihazı kullanıldı. Elde edilen veriler Windows WIN 2000 programı ile dökümante edildi. KOAH olan hastalara rutin medikal tedavinin dışında göğüs hastalıklarının önerileri doğrultusunda preoperatif dönemde inhaler bronkodilatatör, teofilin türevi ilaçlar (oral ve intravenöz infüzyon şeklinde) verildi.

\subsection{Istatistiksel Analiz}

İstatistiksel analizler SPSS 15.0 paket programında yapıldı. Veriler ortalama standart sapma ve yüzde değerler olarak verildi. İki grup arası farkın karşılaştırılmasında Mann Whitney U testi, kategorik değişkenlerin karşılaştırılmasında $\chi$-kare testi, bağımlı grupların karşılaştırılmasında Wilcoxon Signed Ranks testi uygulandı. $\mathrm{p}<0.05$ değerler anlamlı olarak kabul edildi.

\section{Bulgular ve Tartışma \\ 3.1 Bulgular}

Yaş ortalamas1 Grup 1'de $59.5 \pm 11.1$, Grup 2'de $59.1 \pm$ 10.8 idi. Grup 1'de 16 hasta (\%66.7) 64 yaşından küçük, 8 hasta (\%33.7) 65 yaşından büyük iken kontrol grubunda 17 hasta (\%65.4) 64 yaşından küçük, 9 hasta (\%34.6) 65 yaşından büyüktü ( $\mathrm{p}=0.924)$ (Tablo 1-2). 
Tablo 1. Preoperatif demografik verilerin gruplara göre dağılımı

\begin{tabular}{|l|l|c|c|}
\hline \multicolumn{2}{|c|}{} & $\begin{array}{c}\text { Grup 1 } \\
\text { Sayı (\%) }\end{array}$ & $\begin{array}{c}\text { Grup 2 } \\
\text { Sayı (\%) }\end{array}$ \\
\hline \multirow{3}{*}{ Sigara } & İçen & $18(\% 75)$ & $20(\% 76.9)$ \\
\cline { 2 - 4 } & İçmeyen & $6(\% 25)$ & $6(\% 23.1)$ \\
\hline \multirow{3}{*}{ Cinsiyet } & Erkek & $19(\% 79.2)$ & $26(\% 100)$ \\
\hline \multirow{3}{*}{ Yaş } & Kadın & $5(\% 20.8)$ & $0(\% 0)$ \\
\hline Preoperatif FEV1<1.25 L/sn & $<64$ & $16(\% 66.7)$ & $17(\% 65.4)$ \\
\cline { 2 - 4 } & $\geq 65$ & $8(\% 33.3)$ & $0(\% 34.6)$ \\
\hline
\end{tabular}

FEV: Forced expiratory volume

Tablo 2. Grupların yaş ve postoperatif verileri

\begin{tabular}{|l|c|c|}
\hline & Grup 1 & Grup 2 \\
\hline Yaş & $\begin{array}{c}59.5 \pm \\
11.1\end{array}$ & $59.1 \pm 10.8$ \\
\hline Ekstübasyon süresi & $16.5 \pm 2.6$ & $14.9 \pm 2.7$ \\
\hline Yoğun bakım süresi & $2.1 \pm 0.8$ & $2.1 \pm 0.8$ \\
\hline $\begin{array}{l}\text { Hastanede kalma } \\
\text { süresi }\end{array}$ & $13.8 \pm 5.4$ & $10.1 \pm 2.5$ \\
\hline
\end{tabular}

Veriler ortalama \pm standart deviasyon olarak belirtilmiştir.

Cinsiyet dağılımına bakıldığında Grup 1'de 19 hasta (\%79.2) erkek, 5 hasta (\%20.8) kadın iken Grup 2'de 26 hastanın hepsi $(\% 100)$ erkekti $(\mathrm{p}=0.14)$ (Tablo 1). Preoperatif dönemde her iki grup arasında demografik bulgular açısından önemli fark olmadığı görüldü.

Hastalar sigara kullanımı yönünden değerlendirildiğinde Grup 1'de 18 hasta $(\% 75)$ sigara içiyorken 6 hasta (\%25) sigara içmiyordu. Kontrol grubunda ise 20 hasta (\%76.9) sigara içiyorken 6 hasta (\%23.1) sigara içmiyordu. Sigara içiciliği yönünden iki grup arasında anlamlı bir fark yoktu_(p=0.874) (Tablo 1).

Mekanik ventilasyon süresileri karşılaştırıldığında, Grup 1 'de $(16.5 \pm 2.3$ saat $)$, kontrol grubuna göre $(14.9 \pm 2.7$ saat) anlamlı şekilde uzun bulunmuştur $(\mathrm{p}=0.0001)$.

Yoğun bakımda kalış sürelerine bakıldığında Grup 1'de (2.1 \pm 0.8$)$, Grup 2'ye $(2.1 \pm 0.8)$ göre bir fark görülmemiş $(\mathrm{p}=0.988)$ iken hastanede kalış sürelerine bakıldığında Grup 1'de 13.8 土 5.4 gün, Grup 2'de $10.1 \pm$ 2.5 gün olup aradaki fark istatistiksel olarak anlamlı bulunmuştur ( $\mathrm{p}=0.004)$. (Tablo 2).

Preoperatif ve postoperatif dönemde yapılan SFT'nin karşılaştırılmasında Grup 1 hastalarında, FVC değerinde istatistiksel olarak anlaml azalma bulundu $(\mathrm{p}=0.01)$. Fakat FEV1, FEV1/FVC, PEF, MEF75, MEF50, MEF25, MEF25-75 değerlerinde anlamlı bir fark bulunmadi (Tablo 3).

Grup 2 hastalarında preoperatif ve postoperatif dönemde yapılan SFT'nin karşılaştırılmasında FVC, FEV1, FEV1/FVC, PEF, MEF75, MEF50, MEF25, MEF25-75 değerlerinin hepsinde istatistiksel olarak anlamlı bir fark bulundu (Tablo 4).
Tablo 3. KOAH grubunda preopertif ve postoperatif solunum fonksiyon testleri

\begin{tabular}{|l|l|l|}
\hline & Preoperatif & Postoperatif \\
\hline FVC & $3.0 \pm 0.7$ & $2.5 \pm 0.6$ \\
\hline FEV1 & $1.7 \pm 0.5$ & $1.6 \pm 0.5$ \\
\hline FEV1/FVC & $59.0 \pm 14.8$ & $61.8 \pm 12.7$ \\
\hline PEF & $2.8 \pm 1.5$ & $5.0 \pm 1.8$ \\
\hline MEF75 & $2.3 \pm 1.3$ & $2.3 \pm 1.3$ \\
\hline MEF50 & $1.4 \pm 0.7$ & $1.4 \pm 0.8$ \\
\hline MEF25 & $0.5 \pm 0.3$ & $0.5 \pm 0.3$ \\
\hline MEF25-75 & $1.1 \pm 0.5$ & $1.1 \pm 0.7$ \\
\hline
\end{tabular}

FVC: Forced vital capacity, FEV: Forced expiratory volume, PEF: Peak expiratory flow MEF: Mean expiratory flow

Tablo 4. KOAH olmayan grupta preoperatif ve postoperatif solunum fonksiyon testleri

\begin{tabular}{|l|l|l|}
\hline & Preoperatif & Postoperatif \\
\hline FVC & $3.9 \pm 0.7$ & $3.0 \pm 0.7$ \\
\hline FEV1 & $3.0 \pm 0.6$ & $2.1 \pm 0.5$ \\
\hline FEV1/FVC & $75.3 \pm 6.8$ & $70.8 \pm 10.2$ \\
\hline PEF & $5.0 \pm 1.8$ & $3.6 \pm 1.4$ \\
\hline MEF75 & $4.6 \pm 1.7$ & $3.3 \pm 1.3$ \\
\hline MEF50 & $3.2 \pm 0.9$ & $2.3 \pm 0.9$ \\
\hline MEF25 & $1.1 \pm 0.5$ & $0.6 \pm 0.2$ \\
\hline MEF25-75 & $2.6 \pm 0.7$ & $1.7 \pm 0.6$ \\
\hline
\end{tabular}

FVC: Forced vital capacity, FEV: Forced expiratory volume, PEF: Peak expiratory flow MEF: Mean expiratory flow 


\subsection{Tartışma}

KOAH, kalıcı bir hava sınırlanması ve küçük hava yollarının remodelingi ile karakterize bir hastalıktır [12]. KOAH hastasının akciğerinde hava akımı sınırlamasının neden olduğu kronik hipoksi, anjiyotensin dönüştürücü enzimin (ACE) aktivitesini artırır ki bu da periferik oksijen kullanımını ve solunum kası fonksiyonunu daha da olumsuz etkiler. Artmış ACE aktivitesi, renin anjiyotensin aldosteron sistem (RAAS) aktivasyonunu artırarak hücre proliferasyonuna, hipertrofiye, vazokonstrüksiyona ve pulmoner vasküler yatağın inflamasyonuna neden olur. Dahası aldosteronun da pulmoner vasküler ağda benzer etkiye sahip olduğu bildirildi [13, 14]. Patolojik akciğer dokusundaki remodeling sonucu oluşan inflamasyon, inflamatuar hücreleri indükleyerek ve aynı zamanda anjiyogenetik mediatörlerin seviyesini artırarak anjiyogenezise neden olur. İnflamasyonla birlikte anjiyogenez, solunum yollarının yeniden şekillenmesinde önemli bir rol oynar ki bu durum KOAH hastalarında sadece akciğerlerde değil ekstrapulmoner organlar üzerinde de olumsuz etkilere katkıda bulunur $[15,16]$. Efird ve arkadaşları tarafından yapılan bir çalışmada akciğer dışı morbideteler göz önünde bulundurulduğunda CABG geçiren KOAH hastaları arasında postoperatif inme ve renal yetmezlik KOAH olmayan hastalara göre daha yüksek olduğu tespit edilmiştir [17]. KOAH'1 olan ve olmayan hastalar arasındaki bir diğer önemli fark yara enfeksiyonu bulundu. Meszaros ve arkadaşları tarafindan yapılan çalışmada, KOAH'in sternal insizyon yeri enfeksiyonunda bağımsız bir prediktör faktörü olduğu tespit edilmiş [18].

Kardiyak cerrahi geçirecek hastalarda KOAH gibi ciddi akciğer hastalığının etkisi potansiyel olarak tehlikeli olarak değerlendirilir, rölatif kontraendikasyon olarak kabul edilirdi [19]. CABG geçirecek hastalarda $\mathrm{KOAH}$ postoperatif morbidite ve/veya mortalite için bağımsız bir risk faktörü olarak değerlendirilirdi $[20,21]$. CPB'ın başarılı bir şekilde kullanıma girmesiyle birlikte, pulmoner fonksiyonlar üzerine olan olumsuz etkileri görülmeye başlandı [22]. Kirklin 1964 yılında açık kalp cerrahisi sonrası gelişen pulmoner disfonksiyona dikkati çekmiş ve preoperatif dönemde ileri derecede bozulmuş pulmoner fonksiyonları olan hastaların açık kalp cerrahisi sonrasında çok ciddi solunum sorunları ile karşılaştığını belirtmiştir. Ancak anestezi, kalp koruma yöntemleri ve cerrahi tekniklerin yanı sıra preoperatif pulmoner değerlendirme ve medikal optimizasyondaki son gelişmelerden dolayı yüksek riskli $\mathrm{KOAH}$ hastalarında bile kabul edilebilir mortalite ve morbidite ile CABG yapmak mümkün hale gelmiştir. Giderek daha fazla çalışma hafif ve orta KOAH'lı hastalarda postoperatif mortalite ve morbidite oranlarının $\mathrm{KOAH}$ olmayan hastalardan daha yüksek bir riski olmadığını göstermiştir [23, 24]. Ancak son zamanlarda Çin'de yapılan bir araştırmaya göre KOAH'ın halen CABG sonrası postoperatif mortalite için bağımsız bir risk faktörü olduğu ileri sürülmüştür [25].

$\mathrm{KOAH}$ geniş bir hastalık yelpazesini barındırdığı için tanı koymada yardımcı kriterlere ihtiyaç duyulur.
Solunum fonksiyon testlerinde FEV1/FVC $<0.7$ ve FEV1 $<\% 80$ olması, öksürük, balgam, nefes darlığı ve hasta özgeçmişinde KOAH'a neden olabilecek risk faktörlerine maruziyetin bulunması tanı koymamızı kolaylaştırır.

Çalışmalar göstermiştir ki nefes darlığı şikayeti olan KOAH'lı hastaların sadece \%50'den daha azının doktor tanısı mevcuttur. Bizim çalışmamızda grup 1'deki hastaların 17'sinin (\%70.8) daha önce KOAH tanıs1 olmayıp preoperatif dönemde yaptığımız SFT ile tanı konulmuştur.

Preoperatif FEV1 değerinin \%50'dan küçük olması CABG olacak KOAH olan hastalarda en önemli prognostik faktördür. Hafif $\mathrm{KOAH}$ yani preoperatif değerlendirmede FEV1'i \% 70'in üzerinde olan hastalar, orta (FEV1 \%70 ile \%50 arasinda) ve ciddi (FEV1 \%50 ile \%35 arasinda) $\mathrm{KOAH}$ olanlara göre $\mathrm{CABG}$ ameliyatını daha iyi tolere etmektedir [26].

Grover ve arkadaşları, preoperatif KOAH bulunan hastaların FEV1 değerlerinin postoperatif mortalite ile ilişkili olduğunu bir çalışmasında bildirmiştir. Preoperatif FEV1 değeri $1.25 \mathrm{~L} / \mathrm{sn}$ 'den büyük olan KOAH hastalarının operasyon mortalitesi \%3.8 iken, preoperatif FEV1 değeri $1.25 \mathrm{~L} / \mathrm{sn}$ 'den küçük olan KOAH hastalarının operasyon mortalitesi \%11.7 olarak rapor etmişler [10]. Bizim çalıșmamızda preoperatif FEV1 değeri $1.25 \mathrm{~L} / \mathrm{sn}$ 'den küçük olan 4 hasta $(\% 8)$ bulunmakta olup mortaliteye rastlanmamıştır (Tablo 1). Sigara, KOAH gelişiminde çok önemli bir rol oynamaktadır. Sigara içme, postoperatif pulmoner komplikasyonlar, özellikle de uzamıș ventilatör desteği için risk faktörü olarak kabul edilir. Sigara kullanımı hava yolu sekresyonu artışı ile birlikte bronşiyal irritasyona, mukosiliyer temizlemede kötüleşme ve doku oksijen kullanımının bozulması sonucu karboksihemoglobin seviyelerinde artışa neden olur. Postoperatif dönemdeki sigaraya bağlı komplikasyonları en aza indirmek için preoperatif 8 haftalık sigarasız dönem gerekmektedir [27]. Sigara aynı zamanda koroner arter hastalığı (KAH) içinde bir risk faktörü olduğu için $\mathrm{KOAH}$ ile birlikteliği sik görülmektedir [10]. Bizim çalışmamızda grup 1 hastaların 18 'nde $(\% 75)$, grup 2 hastaların 20'sinde (\%76.9) sigara kullanım öyküsü mevcuttu.

Postoperatif dönemdeki pulmoner komplikasyonlar; KOAH olan hastalarda s1k rastlanmakta, hastanın yoğun bakımda kalış süresini ve mekanik ventilasyon ihtiyacını uzatmakta, hastane maliyetleri ile mortalite ve morbiditeyi arttırmaktadır. CPB, pulmoner fonksiyon üzerine olumsuz etkilerini alveolar stabiliteyi bozarak, bunu da kompleman sistem aktivasyonu, pulmoner yatakta nötrofil aktivasyonu, serbest oksijen radikallerinin salınmasını sağlayarak ve alveolar surfaktanın yapısını değiştirerek yapmaktadır [28]. Roller ve centrifugal pompalar kan travmasina neden olarak solunum sistemi ve diğer sistemler üzerine olumsuz etkileri olan vasoaktif maddelerin salınmasına yol açar. Ayrıca lökosit sekestrasyonuna ve platelet aktivasyonuna neden olur. Tüm bunlar postoperatif komplikasyonların gelişmesine katkıda bulunur. 
Ultrafiltrasyon ve lökosit filtrelerinin intraoperatif kullanımıyla hem renal yetmezlikli hem de akciğer fonksiyonları bozuk hastalarda bu olumsuz etkilerin azaltılması amaçlanmaktadır.

Değişen solunum yolu florası ve CPB'ın immünsupresif etkisinden dolayı $\mathrm{KOAH}$ olan hastalarda alt solunum yolu enfeksiyonlarının sıklığı da artmıştır. Bu nedenle postoperatif dönemde solunum problemleri ve pnömoni gibi komplikasyonlar daha sik izlenmektedir [29]. Ried ve arkadaşları [30] ile Samuels ve arkadaşları tarafından farklı zamanlarda yapılan çalışmalarda [5] kalp cerrahisi geçiren KOAH'lı hastalarda pnömoni oranlarının daha belirgin olduğu bulunmuştur. Bizim çalışmamızda KOAH olan hastalarda postoperatif pnömoniye rastlanmamıştır. Bu hastaların yoğun bakım kalış süreleri uzamış, maliyeti artmıştır. Ayrıca yapılan bir çalışmada intraoperatif dönemde düşük tidal völümle ventilasyonun akciğer fonksiyonlarını koruyucu etkisi ve postoperatif solunum yolu komplikasyonlarını azaltıcı etkiside tespit edilmiştir [31]. Mekanik ventilasyon zamanları (16.5 \pm 2.6 saat) KOAH olan grupta, kontrol grubu mekanik ventilasyon zamanı $(14.9 \pm 2.7$ saat $)$ ile karşılaştırıldığında uzun bulunmuştur $(\mathrm{p}=0.0001)$. Türkay ve arkadaşlarının yaptığı çalışmada mekanik ventilasyon zamanının ve yoğun bakımda kalma sürelerinin uzadığı görülmüştür [32]. Ancak bizim çalışmada yoğun bakımda kalma süreleri karşılaştırıldığında anlamlı bir farkın olmadığı gözlendi $(\mathrm{p}=0.988)$.

CABG geçiren KOAH'lı hastalarda morbidite yaş ile birlikte artış gösterir ve KAH ile KOAH birlikteliğinde belirgin bir erkek üstünlüğü vardır. Bizim çalışmamızda $\mathrm{KOAH}$ grubundaki hastaların yaş ortalamasının (59.5 \pm 11.1) kontrol gruba oranla $(59.1 \pm 10.8)$ anlamlı olmadığ görülürken $(\mathrm{p}=0.953), \mathrm{KOAH}$ grubunda hastaların $\% 79.2$ 'si erkekti.

Hastanede kalış süreleri de iki grup arasında farklılık göstermektedir. Grup 1'deki hastanede kalış süresi 13.8 \pm 5.4 gün iken, bu süre Grup 2'de $10.1 \pm 2.5$ gün olup bu değerler istatistiksel olarak değerlendirildiğinde anlamlı bulunmuştur $(\mathrm{p}=0.004)$. Verilen bu bilgi yapılan diğer çalışmalarca da desteklenmektedir [33, 34].

Açık kalp cerrahisi için programlanan KOAH'lı hastalara optimal akciğer fonksiyonları ve en az hava yolu sekresyonunu amaçlayarak hazırlayıcı pulmoner rejim uygulanmalıdır. Bu rejim sigaranın bırakılması, yoğun inhaler bronkodilatatör tedavi, pürülan sekresyon ve öksürüğü olan hastalarda oral antibiyotik kullanımını içerir. Hastalara cerrahi öncesi solunum egzersiz cihazı ile çalışma, öksürme ve nefes alıp verme teknikleri öğretilmeli, önemli bronkospastik komponenti olan hastalarda, kısa süreli oral kortikosteroid tedavisi verilmelidir. Basit ve ucuz olan bu hazırlıklar postoperatif pulmoner komplikasyonların sıklığını önemli ölçüde azaltır [5, 35].

\section{Sonuç}

Çalışmamızda CABG'nin, KOAH olan hastaların akciğer fonksiyonları üzerine önemli etkileri olduğu görülmektedir. $\mathrm{KOAH}, \mathrm{CABG}$ geçiren hastalarda mekanik ventilatör ve yatış sürelerini uzatmaktadır. Bu durum komplikasyon gelişmesi için bir risk faktörü olmakla birlikte ciddi hastane maliyeti oluşturmaktadır. Bütün bunlar göz önüne alındığında $\mathrm{CABG}$ geçirecek hastalara preoperatif dönemde $\mathrm{KOAH}$ tanısının konması ve şiddetinin belirlenmesi; preoperatif dönemde gerekli tedavinin başlanması, operasyonun pulmoner dekompensasyon gibi uygun bir zamanda planlanmas1, intraoperatif ve postoperatif dönemde takip edilecek stratejiler ve alınacak önlemler açısından çok önemlidir. $\mathrm{Bu}$ nedenle CABG cerrahisi geçirecek hastalara preoperatif dönemde solunum fonksiyon testi rutin olarak uygulanmalidir.

\section{Referanslar}

1. Rabe, K.F, Watz H, Chronic obstructive pulmonary disease, Lancet, 2017, 389, 1931-1940.

2.Zhao, H, Li, L, Yang, G, et al., Postoperative outcomes of patients with chronic obstructive pulmonary disease undergoing coronary artery bypass grafting surgery A meta-analysis, Medicine, 2019, 98,

3. O'Boyle, F, Mediratta, N, Chalmers, J, et al., Long-term survival of patients with pulmonary disease undergoing coronary artery bypass surgery, European Journal of Cardiothoracic Surgery, 2013, 43, 697-703.

4.Ho, C.H, Chen, Y.C, Chu, C.C, et al, Postoperative complications after coronary artery bypass grafting in patients with chronic obstructive pulmonary disease, Medicine, 2016, 95(8), e2926.

5. Samuels, L.E, Kaufman, M.S, Morris, R.J, et al., Coronary artery bypass grafting in patients with COPD, Chest, 1998, 113, 878-882.

6.U.S. Department of Health and Human Services. The Health Consequences of Smoking. A Report of the Surgeon General, 2004.

7. Türkoğlu, T. Kardiyopulmoner Bypassa Girilmeden (Off-Pump) Atan Kalpte Ve Kardiyopulmoner Bypass Kullanılarak Kardiyak Arrest İle Uygulanan Koroner Bypass Cerrahisi Sonrası Atrial Fibrilasyon Gelişiminin Karşılaştırılması [Tez]. İstanbul: Dr. Siyami Ersek Göğüs Kalp Ve Damar Cerrahisi Eğitim Ve Araştırma Hastanesi, 2004.

8. American Thoracic Society/European Respiratory Society statement: standards for the diagnosis and management of individuals with alpha-1 antitrypsin deficiency, American Journal of Respiratory and Critical Care Medicine, 2003, 168, 818-900.

9.Hnizdo, E, Sullivan, P.A, Bang, K.M, et al., Association between chronic obstructive pulmonary disease and employment by industry and occupation in the US population: a study of data from the Third National Health and Nutrition Examination Survey, American Journal of Epidemiology, 2002, 156 (8), 738-746.

10. Grover, F.L, Hammermeister, K.E, Burchfiel, C, Initial report of the veterans administration preoperative risk assesment study for cardiac surgery, The Annals of Thoracic Surgery, 1990, 50, 12-26.

11. King, R.C, Reece, T.B, Hurst, J.L, et al, Minimally invasive coronary artery grafting decreases hospital stay and cost, Annals of Surgery, 1997, 225, 805-809.

12. Matarese, A, Santulli, G, Angiogenesis in chronic obstructive pulmonary disease: a translational appraisal, Translational Medicine@UniSa, 2012,3,49-56.

13. Lymperopoulos, A, Rengo, G, Zincarelli, C, et al., An adrenal betaarrestin 1-mediated signaling pathway underlies angiotensin IIinduced aldosterone production in vitro and in vivo, Proceeding of the National Academy of Sciences USA, 2009, 106, 5825-5830.

14. Dabul, S, Bathgate-Siryk, A, Valero, T.R, et al., Suppression of adrenal barrestin1 - dependent aldosterone production by ARBs: head-to-head comparison, Scientific Reports, 2015, 5, 8116.

15. Kropski, J.A, Richmond, B.W, Gaskill, C.F, et al., Deregulated angiogenesis in chronic lung diseases: a possible role for lung 
mesenchymal progenitor cells (2017 Grover Conference Series), Pulmonary Circulation, 2018, 8, 2045893217739807.

16. Mascitelli, L, Pezzetta, F, Goldstein M.R, Inhibition of the reninangiotensin system in severe COPD, European Respiratory Journal, 2008, 32, 1130, author reply 1131.

17. Efird, J.T, Griffin, W, O’Neal, W.T, et al., Long-term survival after cardiac surgery in patients with chronic obstructive pulmonary disease, American Journal of Critical Care, 2016, 25, 266-276.

18. Meszaros, K, Fuehrer, U, Grogg, S, et al, Risk factors for sternal wound infection after open heart operations vary according to type of operation, The Annals of Thoracic Surgery, 2016, 101, 1418-1425.

19. Morse, D.P, Indications for open-heart surgery: risks, and results, Springfield, III: Charles C Thomas, 1963.

20. Magovern, J.A, Sakert, T, Magovern, G.J, et al, A model that predicts morbidity and mortality after coronary artery bypass graft surgery, Journals of the American College of Cardiology, 1996, 28, 11471153.

21.Higgins, T.L, Estafanous, F.G, Loop, F.D, et al., Stratification of morbidity and mortality outcome by preoperative risk factors in coronary artery bypass patients. A clinical severity score, JAMA 1992, 267, 2344-2348.

22. Gibbon, J.H, Application of a mechanical heart-lung apparatus to cardiac surgery, Minnesota Medicine, 1954, 37, 171.

23. Angouras, D.C, Anagnostopoulos, C.E, Chamogeorgakis, T.P, et al., Postoperative and long-term outcome of patients with chronic obstructive pulmonary disease undergoing coronary artery bypass grafting, The Annals of Thoracic Surgery, 2010, 89, 1112-1118.

24. Michalopoulos, A, Geroulanos, S, Papadimitriou, L, et al., Mild or moderate chronic obstructive pulmonary disease risk in elective coronary artery bypass grafting surgery, World Journal of Surgery, 2001, 25, 1507-1511

25.Zheng, Z, Zhang, L, Hu, S, et al., Risk factors and in-hospital mortality in Chinese patients undergoing coronary artery bypass grafting: analysis of a large multi-institutional Chinese database, The Journal of Thoracic and Cardiovascular Surgery, 2012, 144, 355359 .

26. Kurulay, E, Cingoz, F, Kilic, S, et al., Supraventricular tachyarrythmia prophylaxis alter coronary artery surgery in chronic obstructive pulmonary disease patients (early amiodarone prophylaxis trial), European Journal of Cardiothoracic Surgery, 2004, 25, 224-230.

27. Warner, M.A, Divertie, M.B, Tinker, J.H, Preoperative cessation smoking and pulmonary complications in coronary artery bypass patients, Anesthesiology, 1984, 60, 380-383.

28. Güler, M, Kirali, K, Toker, M.E, et al. Different CABG methods in patients with chronic obstructive pulmonary disease, Annals of Thoracic Surgery, 2001, 71(1), 152-7.

29. Gass, G.D, Olsen, G.N, Preoperative pulmonary functional testing to predict postoperative morbidity and mortality, Chest, 1986, 89, 127 135 .

30. Ried, M, Unger, P, Puehle, T, et al., Mild-to-moderate COPD as a risk factor for increased 30-day mortality in cardiac surgery, The Thoracic and Cardiovascular Surgeon, 2010, 58, 387-391.

31. Ozyaprak, B, Kahraman, N, The assessment of the effect of low tidal volume ventilation on postoperative respiratory functions during cardiopulmonary bypass in heart surgery, International Journal of Clinical and Experimental Medicine, 2019, 12(6), 7426-7433.

32. Türkay, C, Akbulut, E, Özbudak, Ö, Gölbaşı, İ, ve ark., Koroner bypass cerrahisi uygulanan hastalarda kronik obstrüktif akciğer hastalığının mortalite ve morbiditeye etkisi, Türk Göğüs Kalp Damar Cerrahisi Dergisi, 2000, 8(3), 678-681.

33. Rosen, A.B, Humphries, J.O, Muhlbaier, L.H, Kiefe, C.I, Kresowik, T, Peterson, E.D, Effect of clinical factors on length of stay after coronary artery bypass surgery: results of the cooperative cardiovascular Project, American Heart Journal, 1999, 138, 69-77.

34. Braun, S.R, Birnbaum, M.L, Chopra, P.S, Pre and postoperative pulmonary function abnormalities in coronary artery revascularization surgery, Chest, 1978, 73, 316-320.

35. Kandemir, Ö, Büyükateş, M, Turan, S.A, ve ark, Kronik obstrüktif akciğer hastalığının yaygın olduğu bir bölgede koroner bypass cerrahisi sonuçları, Türk Göğüs Kalp Damar Cerrahisi Dergisi, 2007, 15(2), 113-117.

http://edergi.cbu.edu.tr/ojs/index.php/cbusbed isimli yazarın CBU-SBED başlıklı eseri bu Creative Commons Alıntı-Gayriticari4.0 Uluslararas1 Lisansı ile lisanslanmıştır.

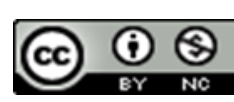

